\title{
Identification and molecular characterization of an efflux system involved in Pseudomonas putida $S 12$ multidrug resistance
}

\author{
Jasper Kieboom and Jan A. M. de Bont
}

Division of Industrial Microbiology, Department of Food Technology and Nutritional Sciences, Wageningen Agricultural University, PO Box 8129, 6700 EV Wageningen, The Netherlands
Author for correspondence: Jasper Kieboom. Tel: +31 317 484412. Fax: +31 317484978. e-mail: jasper.kieboom@imb.ftns.wau.nl

\begin{abstract}
The authors previously described srpABC, an operon involved in protondependent solvent efflux in the solvent-tolerant Pseudomonas putida S12. Recently, it was shown that organic solvents and not antibiotics induce this operon. In the present study, the authors characterize a new efflux pump, designated ArpABC, on the basis of two isolated chloramphenicol-sensitive transposon mutants. The arpABC operon is involved in the active efflux of multiple antibiotics, such as tetracycline, chloramphenicol, carbenicillin, streptomycin, erythromycin and novobiocin. The deduced amino acid sequences encoded by the three genes involved show a striking resemblance to proteins of the resistance/nodulation/cell division family, which are involved in both organic solvent and multiple drug efflux. These findings demonstrate that ArpABC is highly homologous to the MepABC and TtgABC efflux systems for organic solvents and multiple antibiotics. However, ArpABC does not contribute to organic solvent tolerance in P. putida $\mathrm{S} 12$ but is solely involved in multidrug resistance.
\end{abstract}

Keywords: solvent tolerance, multidrug resistance, efflux

\section{INTRODUCTION}

It is well known that several strains within the family Pseudomonadaceae show significant intrinsic resistance to a wide variety of structurally unrelated compounds, such as antimicrobial agents and organic solvents (for reviews see Nikaido, 1996; Paulsen et al., 1996; Isken \& de Bont, 1998; Kieboom et al., 2000). In the case of Pseudomonas aeruginosa it was thought that a very low, non-specific permeability was the main cause of resistance to antibiotics (Nikaido, 1994). In the case of Pseudomonas putida several changes at the level of the membrane contribute to organic solvent tolerance (Weber \& de Bont, 1996; Isken \& de Bont 1998). Nevertheless, the exceptional resistance of Pseudomonadaceae cannot be explained solely by the low permeability of the outer membrane and by changes at the level of the membrane. Not surprisingly, efflux systems have been identified that contribute to the exceptional resistance of these strains. These efflux systems, which belong to the resistance/nodulation/cell division (RND) family of transporters, consist of three

Abbreviation: RND family, resistance/nodulation/cell division family. The GenBank accession number for the arp sequence is AF183959. components: the inner membrane transporter protein (RND protein), which is attached via a membrane fusion protein (MFP) to an outer membrane protein (OMP) (Saier et al., 1994). The OMP is thought to be an outer membrane channel by which to circumvent the outer membrane barrier, allowing the pumped molecule to be released into the medium (Dinh et al., 1994).

In the solvent-tolerant $P$. putida strain $\mathrm{S} 12$ it was shown that the energy-dependent efflux of organic solvents was the key factor in organic solvent tolerance via the organic solvent transporter SrpABC (Kieboom et al., 1998a). Similar efflux systems for the active removal of organic solvents have been found in other P. putida strains. These RND-type efflux systems, encoded by ttgABC (Ramos et al., 1998), ttgDEF (Mosqueda \& Ramos, 2000) and mepABC (Fukumori et al., 1998), are involved in the active efflux of toxic compounds such as toluene, $p$-xylene and styrene. In the case of the multidrug-resistant $P$. aeruginosa four efflux systems have been described: MexAB-OprM (Poole et al., 1993), MexCD-OprJ (Poole et al., 1996), MexEF-OprM (Kohler et al., 1997) and AmrAB (Westbrock-Wadman et al., 1999). These systems contribute to the energydependent efflux of a wide variety of antimicrobial agents such as $\beta$-lactams, tetracycline, fluoroquinolones 
and chloramphenicol. The interesting question now arises whether the RND-type transporters are able to export both antibiotics and solvents. Indications so far confirm that these pumps have dual pumping capacity. The mex-encoded efflux systems have recently been shown to be involved in the efflux of organic solvent in P. aeruginosa ( $\mathrm{Li}$ et al., 1998). Moreover, solventsensitive mutants of $P$. putida DOT-T1E and $P$. putida KT2442 became more sensitive to antibiotics such as tetracycline, chloramphenicol and ampicillin, suggesting the active removal of multiple antibiotics by these efflux systems (Ramos et al., 1998; Fukumori et al., 1998).

We have now studied this aspect at the molecular level and have found a new efflux system in P. putida S12 that is involved in the intrinsic resistance of this strain to a wide variety of structurally unrelated antibiotics. Sequence analysis showed that this efflux system is highly homologous to the solvent/antibiotic transporters MepABC and $\operatorname{Ttg} A B C$. Moreover, we demonstrate that ArpABC in P. putida S12 is only involved in multidrug resistance and not in tolerance towards organic solvents.

\section{METHODS}

Bacterial strains, plasmids and growth of the strains. $P$. putida S12 (ATCC 700801) (Hartmans et al., 1989), a wild-type strain capable of growth at supersaturated solvent concentrations
(Weber et al., 1993), was the object of the present investigation. Mutant strains of $P$. putida S12 generated in this study and those generated previously are shown in Table 1. Escherichia coli DH5 $\alpha$ (Yanisch-Perron et al., 1985) was utilized as host strain for all recombinant plasmids. The cloning vectors used and the plasmids generated in this study are shown in Table 1. Luria-Bertani (LB) broth (Sambrook et al., 1989) was used as complete medium. For electroporation, cells were grown in $10 \mathrm{~g}$ tryptone $\mathrm{l}^{-1}$ and $5 \mathrm{~g}$ yeast-extract $\mathrm{l}^{-1}$. Solid media contained $2 \%$ agar. Ampicillin $\left(100 \mu \mathrm{g} \mathrm{ml}^{-1}\right)$, kanamycin $\left(50 \mu \mathrm{g} \mathrm{ml} \mathrm{m}^{-1}\right)$, gentamicin $\left(10 \mu \mathrm{g} \mathrm{ml}^{-1}\right)$ and tetracycline $\left(50 \mu \mathrm{g} \mathrm{ml}^{-1}\right)$ were added to the medium to maintain recombinant plasmids in E. coli and P. putida. The E. coli strains were routinely cultured at $37^{\circ} \mathrm{C}$ and P. putida strains were grown at $30^{\circ} \mathrm{C}$.

Generation and screening of $\mathrm{Tn} M o d-\mathrm{KmO}$ insertion mutants. The plasposon TnMod-KmO was introduced into P. putida S12 by electroporation (Dennis \& Sokol, 1995). Kanamycinresistant transposon mutants were tested for their ability to grow on LB agar plates supplemented with $100 \mu \mathrm{g}$ chloramphenicol $\mathrm{ml}^{-1}$ and $50 \mu \mathrm{g}$ kanamycin $\mathrm{ml}^{-1}$. Mutants were incubated at $30^{\circ} \mathrm{C}$ for $24 \mathrm{~h}$. Mutants unable to grow in the presence of $100 \mu \mathrm{g}$ chloramphenicol $\mathrm{ml}^{-1}$ were selected.

DNA techniques. Total genomic DNA from $P$. putida strains was prepared by the CTAB procedure (Ausubel et al., 1991). Plasmid DNA was isolated by the alkaline SDS lysis method of Birnboim \& Doly (1979). DNA was digested with restriction enzymes and ligated with T4 ligase as recommended by the supplier (Life Technologies). DNA restriction fragment and

Table 1. Strains and plasmids used in this study

\begin{tabular}{|c|c|c|}
\hline Strain/plasmid & Relevant characteristics* & Source or reference \\
\hline \multicolumn{3}{|l|}{ Strains } \\
\hline P. putida S12 & $A p^{r} C m^{r} \operatorname{srp} A B C^{+} \operatorname{arp} A B C^{+}$ & Hartmans et al. (1989) \\
\hline P. putida JK1 & $A p^{r} \mathrm{Cm}^{\mathrm{r}} \operatorname{srp} B \nabla \mathrm{Tn} M o d-\mathrm{KmO}$ & Kieboom et al. (1998a) \\
\hline P. putida CM1 & $\mathrm{Ap}^{\mathrm{r}} \mathrm{Cm}^{\mathrm{s}} \operatorname{arp} B \nabla \mathrm{Tn} M o d-\mathrm{KmO}$ & This study \\
\hline P. putida CM2 & $\mathrm{Ap}^{\mathrm{r}} \mathrm{Cm}^{\mathrm{s}}$ arpC $\mathrm{C} \mathrm{Tn} M o d-\mathrm{KmO}$ & This study \\
\hline P. putida DM1 & $\mathrm{Ap}^{\mathrm{r}} \mathrm{Cm}^{\mathrm{s}} \operatorname{srp} B \nabla \mathrm{Tn} M o d-\mathrm{KmO} \operatorname{arp} A::$ tet $A$-oriR $:: \operatorname{arp} B$ & This study \\
\hline E. coli $\mathrm{DH} 5 \alpha$ & recA1 & Yanisch-Perron et al. (1985) \\
\hline \multicolumn{3}{|l|}{ Plasmids } \\
\hline $\mathrm{pTnMod-KmO}$ & $\mathrm{Km}^{\mathrm{r}}$, pMB1 replicon & Dennis \& Zylstra (1998) \\
\hline pUC18 & $A p^{r}$, cloning vector & Life Technologies \\
\hline pUC19 & $A p^{r}$, cloning vector & Life Technologies \\
\hline pBBR1MCS & $\mathrm{Cm}^{\mathrm{r}}$, cloning vector, REP replicon & Kovach et al. (1994) \\
\hline pUCP22 & $\mathrm{Ap}^{\mathrm{r}} \mathrm{Gm}^{\mathrm{r}}$, cloning vector, pRO1600 replicon & West et al. (1994) \\
\hline pKRZ-1 & $\mathrm{Km}^{\mathrm{r}}$, promoter probe cloning vector & Rothmel et al. (1991) \\
\hline pACYC184 & $\mathrm{Tc}^{\mathrm{r}}$, cloning vector & Calgene \\
\hline pJD105 & pUCP22 containing $\operatorname{srp} A B C$ & Kieboom et al. (1998a) \\
\hline pCM1P & $\mathrm{Km}^{\mathrm{r}} \operatorname{arpBC}$ from chromosomal DNA of $P$. putida CM1 & This study \\
\hline pCM2P & $\mathrm{Km}^{\mathrm{r}} \operatorname{arpBC}$ from chromosomal DNA of $P$. putida CM2 & This study \\
\hline pCM1B & $\mathrm{Km}^{\mathrm{r}}$ arpABC from chromosomal DNA of $P$. putida CM1 & This study \\
\hline pCMPE & pUC18 containing $\operatorname{arpRA}$ & This study \\
\hline pCMC1 & pUCP22 containing $\operatorname{arp} A B$ & This study \\
\hline pCMC2 & pUCP22 containing $\operatorname{arp} A B C$ & This study \\
\hline pKRZ-arp & pKRZ-1 containing $P_{\text {arp }}$ lac $Z$ fusion & This study \\
\hline pTO1 & $\mathrm{Tc}^{\mathrm{r}} \mathrm{Cm}^{\mathrm{s}} \mathrm{pBBR} 1 \mathrm{MCS}$ containing tetA-oriR & This study \\
\hline pSC1 & $\mathrm{Tc}^{\mathrm{r}} \operatorname{arp} A::$ tet $A$-oriR::arpB, pMB1 replicon & This study \\
\hline
\end{tabular}

*Ap, Cm, Km, Gm and Tc represent resistance ( $\mathrm{r}$ ) or sensitivity (s) to ampicillin, chloramphenicol, kanamycin, gentamicin and tetracycline, respectively. 
PCR products were visualized by $0.8 \%$ agarose gel electrophoresis in $45 \mathrm{mM}$ Tris/borate, $1 \mathrm{mM}$ EDTA buffer. DNA from agarose gels was isolated using the method of Vogelstein \& Gillespie (1979). Southern analyses of chromosomal DNA and colony hybridizations were carried out according to Maniatis et al. (1982). Probes were labelled with DIG-dUTP using the PCR DIG Probe Synthesis Kit (Boehringer Mannheim) with the appropriate primers. Southern blot hybridizations were carried out by chemiluminescent detection under high-stringency conditions as described by the supplier (Boehringer Mannheim). Plasmid DNA was introduced into either E. coli DH5 $\alpha$ or P. putida cells by electroporation (Dennis \& Sokol, 1995) using a Gene Pulser (Bio-Rad).

DNA sequences of both strands of the $\operatorname{arp} A B C$ operon were determined by a combination of subcloning and primer walking. All sequencing and PCR reactions were performed using a Gene Amp PCR System 9700 (Perkin-Elmer). Nucleotide sequencing reactions were performed with purified double-strand plasmid DNA using AmpliTaq FS DNA polymerase fluorescent dye terminator reactions (Perkin-Elmer) as recommended by the supplier. Sequencing products were detected using an Applied Biosystems 373A stretch automated DNA sequencer. Nucleotide sequence analysis was performed either with the Lasergene analysis package (DNASTAR) or with the National Centre for Biotechnology Information BLAST server (Altschul et al., 1990).

Construction of pCMC2 for complementation. For the complementation experiments we reconstructed the $\operatorname{arp} A B C$ operon since the clones obtained from P. putida CM1 and CM2 contain the transposon-mutagenized DNA. Therefore, a $2 \cdot 2 \mathrm{~kb}$ BamHI-PstI fragment from pCM1B was cloned into the broad-host-range vector pUCP22; the resulting plasmid was designated pCMC1. A $2.3 \mathrm{~kb}$ Pst I-EcoRI fragment from pCM2P and a $2 \cdot 0 \mathrm{~kb} E c o \mathrm{RI}-P$ st I fragment from pCM1P were ligated into Pst I-digested and alkaline-dephosphatase-treated pCMC1. The resulting plasmid, pCMC2, contained the $\operatorname{arp} A B C$ genes in the same orientation as the lac promoter and was transferred to the mutant strains CM1 and CM2.

Construction of suicide plasmid pSC1. We amplified a 1289 bp fragment containing the tetracycline-resistance gene tet $A$ from pACYC184. The primers 5'-CGGAATTCTCATGTTTGACAGCT-3' and '5'-GCGGTACCTCAGGTCGAGGTGG-3' contain added recognition sites for EcoRI and KpnI, respectively. The reaction mixture $(50 \mu \mathrm{l})$ was treated for $10 \mathrm{~min}$ at $94{ }^{\circ} \mathrm{C}$ followed by 35 cycles of $1 \mathrm{~min}$ at $94^{\circ} \mathrm{C}, 2 \mathrm{~min}$ at $55^{\circ} \mathrm{C}$ and $1 \mathrm{~min}$ at $72^{\circ} \mathrm{C}$ before finishing for $10 \mathrm{~min}$ at $72{ }^{\circ} \mathrm{C}$. This $1.3 \mathrm{~kb}$ EcoRI-KpnI fragment and a $0.7 \mathrm{~kb} K p n \mathrm{I}-$ Sst I fragment from TnMod-KmO, containing the ColE1 origin of replication, were ligated in EcoRI- and SstI-digested pBBR1MCS, resulting in pTO1. The suicide plasmid pSC1 was constructed by ligating a $2 \cdot 0 \mathrm{~kb}$ EcoR I-Sst I fragment from pTO1, a $3.0 \mathrm{~kb}$ PstI-SstI fragment from pCM1P and a $3.0 \mathrm{~kb}$ Pst $\mathrm{I}-$ EcoRI fragment from pCMPE.

Construction of pKRZ-arp and determination of $\beta$-galactosidase activity. PCR reactions for amplifying the region of genomic $P$. putida S12 DNA containing the arp promoter were performed using Super Taq DNA polymerase (SphearoQ). The reaction mixture $(50 \mu \mathrm{l})$ was treated for $10 \mathrm{~min}$ at $94{ }^{\circ} \mathrm{C}$ followed by 35 cycles of $1 \mathrm{~min}$ at $94^{\circ} \mathrm{C}, 1 \mathrm{~min}$ at $58^{\circ} \mathrm{C}$ and $1 \mathrm{~min}$ at $72^{\circ} \mathrm{C}$ before finishing for $10 \mathrm{~min}$ at $72{ }^{\circ} \mathrm{C}$. Primers for this reaction were $5^{\prime}$-CCGCTCGAGTACAACCTCATCTGGCCC-3' and 5'-CGCTCTAGAATTGCATGAGGATCCTCG-3', which amplified a 276 bp fragment corresponding to the region immediately upstream of the $\operatorname{arp} A B C$ genes. The primers contain added recognition sites for $X h o I$ and $X b a I$, respectively. $\beta$-Galactosidase activity in $P$. putida S12(pKRZarp) was determined by growing the cells to late-exponential phase at $30^{\circ} \mathrm{C}$ in $10 \mathrm{ml} \mathrm{LB}$ broth supplemented with inducer. The $\beta$-galactosidase activity in these experiments was determined in triplicate by the method of Miller (1972) using chloroform and SDS to permeabilize the cells.

Determination of solvent tolerance and the MIC of antibiotics. Solvent tolerance of the P. putida strains was determined in duplicate by growing the cells in $10 \mathrm{ml}$ liquid LB medium in $100 \mathrm{ml}$ flasks supplemented with $1 \mathrm{mM}$ magnesium chloride. Toluene and $p$-xylene ( $1 \%$ final concentration) were separately added to identical subcultures in $\mathrm{LB} / \mathrm{MgCl}_{2}$ medium during the early exponential growth phase. The maximal aqueous benzene concentration was determined by adding increasing amounts of benzene. Growth of the cultures was measured $24 \mathrm{~h}$ after solvent addition with no continued growth indicating solvent sensitivity. The MIC for various antibiotics was determined in duplicate by threefold serial dilution in LB broth in microtitre plates. The inoculum was $1 \%$ of an overnight culture and growth was determined by measuring the $\mathrm{OD}_{600}$ after $36 \mathrm{~h}$ at $30^{\circ} \mathrm{C}$.

\section{RESULTS}

\section{Isolation of chloramphenicol-sensitive mutants}

$P$. putida S12 is able to grow in the presence of a wide variety of normally toxic solvents and is relatively resistant to various antibiotics. Chloramphenicol-sensitive mutants were obtained by electroporating the transposon TnMod-KmO into P. putida S12. Over 4000 kanamycin-resistant transposon mutants were constructed, with an overall transformation efficiency for TnMod-KmO of $1.5 \times 10^{3}$ per $\mu$ g DNA. These mutants were tested for growth on solid LB medium supplemented with $100 \mu \mathrm{g}$ chloramphenicol $\mathrm{ml}^{-1}$. Two chloramphenicol-sensitive mutants were isolated and were designated strains CM1 and CM2, respectively.

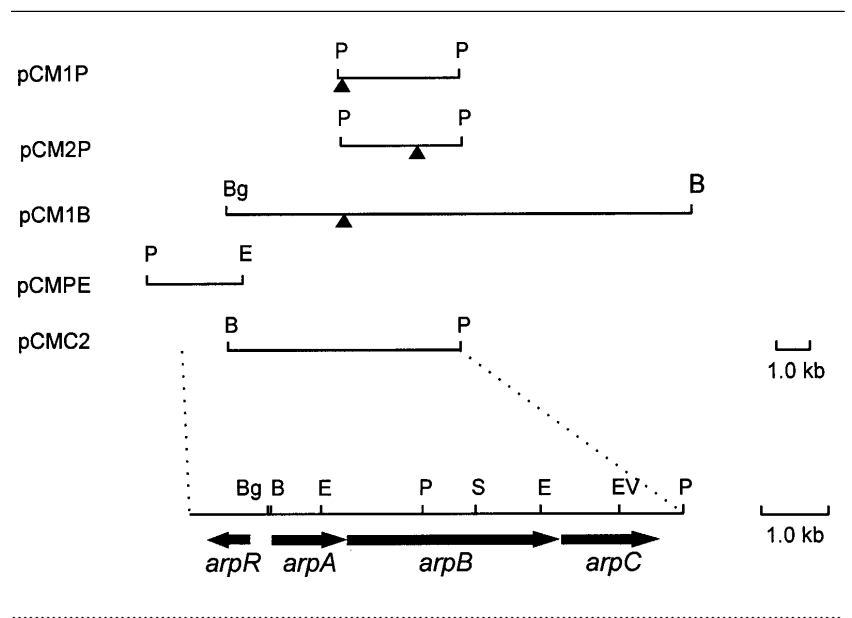

Fig. 1. Restriction maps of the clones derived from the transposon mutants $\mathrm{CM} 1$ and $\mathrm{CM} 2$. A diagram of the arp nucleotide sequence is shown at the bottom, in proportion to the restriction maps and showing the positions of the genes relative to the restriction enzyme cutting sites. The triangles in the restriction maps indicate the location of the inserted plasposon TnMod-KmO in the cloned genomic DNA. 
GGGCGGCCACGCCCCTTAATGCCCCCTTAACACAAAGGGGAACACTCCCTCACAATCCTTAACAAAGTGTCATTTGCGCAGAGCAGGGCTCAAGCGCAGCATATCCAGCCCGGTGTCGA

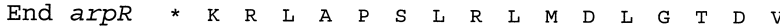

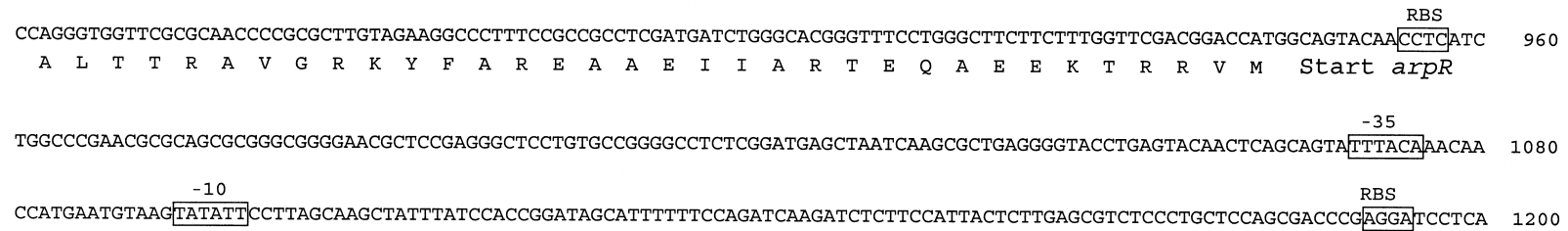

TGCAATTCAAGCCAGCCGTTACCGCTCTGGTTTCCGCCGTCGCCCTGGCAACCCTGCTCAGTGGCTGTAAGAAAGAAGAAGCAGCGCCCGCGGCGCAGGCTCCTCAGGTCGGCGTCGTGA 1320

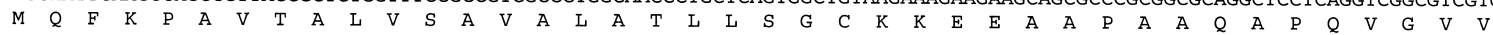

TCGGCGACCGCCTGTCGCAGCTGACCAGCGAGGTCAACCTGTACAAGGCGCTTGGCGGTGGCTGGTACGAGCAGACCGGGCAGGCCAACCAGCAGGCATCGGTGGAAACACCGAAAGGCT 6960

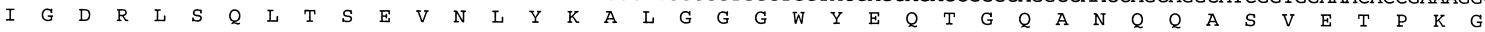
GATCGGCCTTGTTACAGCACAAGCCCACCCTTAGCGGTGGGCTTTGCTTTTTTACTGCCTGTGCCGGCCAGTATCTCTTGGCGATTCACCGTCGCAGCCACCACCGTATTCGCGGGTGAA 7080 * End $\operatorname{arp} C$

Fig. 2. Nucleotide sequence of the relevant portions of a $7313 \mathrm{bp}$ fragment containing the arp genes. The deduced amino acid sequences of the encoded proteins are shown beneath the nucleotide sequence. Termination codons are indicated with an asterisk and putative ribosome-binding sites and a putative $\sigma^{70}$-dependent promoter motif that

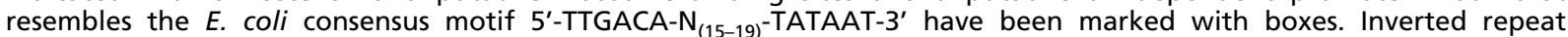
sequences are indicated in black boxes. An arrow indicates the position of TnMod-KmO in $P$. putida CM1 and $P$. putida CM2 (position 3594 and 5738 of the $\operatorname{arp} A B C$ sequence, respectively). The GenBank accession number for the arp sequence is AF183959.

\section{Cloning and analysis of the genes for chloramphenicol resistance}

To characterize the genes for chloramphenicol resistance in $P$. putida S12, the regions of the genome containing the transposon insertion in mutants CM1 and CM2 (both $5.8 \mathrm{~kb}$ ) were cloned. From both mutants a clone was obtained from PstI-digested chromosomal DNA; the clones were designated $\mathrm{pCM} 1 \mathrm{P}$ and $\mathrm{pCM} 2 \mathrm{P}$, respectively. Genomic DNA cut with BamHI from strain CM1 was used to construct the $14 \cdot 0 \mathrm{~kb}$ plasmid pCM1B. Plasmid pCM1B was shown to contain a complete operon, including the inserted TnMod-KmO (Fig. 1). The nucleotide sequence of the operon was determined and screening for similar nucleotide sequences in the GenBank database revealed a significant match with genes encoding multidrug and solvent export pumps. We labelled the genes arp, for antibiotic resistance pump. A diagram of the nucleotide sequence obtained is presented in Fig. 1 to show the relationship of the open reading frames with the three clones pCM1P, pCM2P and $\mathrm{pCM} 1 \mathrm{~B}$. The deduced nucleotide sequences of $\operatorname{arp} A$, $\operatorname{arp} B$ and $\operatorname{arp} C$ encode proteins of 371,1050 and 484 amino acid residues with calculated molecular masses of $40.3,112.8$ and $52.8 \mathrm{kDa}$, respectively. Putative ribosome-binding sites precede the $\operatorname{arp} A B C$ genes and a stable stem-loop structure was found downstream of $\operatorname{arpC}$ that may function as transcriptional terminator (Fig. 2).

\section{Construction of an arpABC mutant of $P$. putida JK1}

The presence of the solvent efflux pump SrpABC in $P$. putida CM1 and CM2 could mask the possible efflux of organic solvent by ArpABC. Therefore, to determine the role of $\operatorname{ArpABC}$ in solvent tolerance we decided to inactivate the $\operatorname{arp} A B C$ gene cluster by site-specific 
Table 2. Determination of the MIC of various antibiotics for the P. putida strains

The MIC for antibiotics was determined in duplicate by threefold serial dilution in LB broth in microtitre plates. The inoculum was $1 \%$ of an overnight culture and growth was determined by measuring the $\mathrm{OD}_{600}$ after $36 \mathrm{~h}$ at $30^{\circ} \mathrm{C}$. ND, Not determined.

\begin{tabular}{|c|c|c|c|c|c|}
\hline \multirow[t]{2}{*}{ Antibiotic } & \multicolumn{5}{|c|}{$\operatorname{MIC}\left(\mu \mathrm{g} \mathrm{ml}^{-1}\right)$ for strain: } \\
\hline & S12 & CM1 & CM2 & CM1 (pCMC2) & CM2(pCMC2) \\
\hline Tetracycline & 16 & 1 & 2 & 16 & 16 \\
\hline Chloramphenicol & 64 & 16 & 16 & 128 & 128 \\
\hline Ampicillin & 256 & 64 & 128 & ND & ND \\
\hline Carbenicillin & 1024 & 4 & 4 & ND & ND \\
\hline Streptomycin & 32 & 8 & 8 & 64 & 64 \\
\hline Erythromycin & 128 & 8 & 4 & 128 & 256 \\
\hline Rifampicin & 64 & 32 & 32 & 32 & 32 \\
\hline Polymyxim B & 16 & 8 & 8 & 8 & 8 \\
\hline Nalidixic acid & 256 & 128 & 128 & 256 & 256 \\
\hline Novobiocin & 1024 & 64 & 128 & 1024 & 1024 \\
\hline Penicillin G & $>4094$ & 2048 & 4094 & ND & ND \\
\hline
\end{tabular}

reciprocal recombination in the solvent-sensitive transposon mutant $P$. putida JK1, creating a srp-arp double mutant. We electroporated $P$. putida JK1 with the suicide plasmid pSC1 (Table 1) replacing part of arpA and $\operatorname{arp} B$ with the ColE1 origin of replication and tetracycline resistance gene, resulting in the srp-arp double mutant $P$. putida DM1. Recombination was confirmed by hybridization of $P$. putida DM1 chromosomal DNA with a probe for the tetA gene (data not shown).

\section{Complementation of $P$. putida mutants}

Complementation experiments were performed to prove that the TnMod-KmO-inserted open reading frames detected in $P$. putida CM1 and CM2 are actually responsible for chloramphenicol resistance. These complemented strains regained chloramphenicol resistance similar to the wild-type levels (Table 2). These results are consistent with the chloramphenicol-resistance phenotype being dependent on expression of the $\operatorname{arp} A B C$ genes. We tested a variety of structurally unrelated antibiotics, which are known substrates for homologous efflux systems of the RND family of transporters (Nikaido, 1996; Paulsen et al., 1996). Mutants CM1 and CM2 were not only sensitive to chloramphenicol but also to a number of other antibiotics (Table 2), demonstrating that a single genetic trait in P. putida S12 is responsible for resistance to the antibiotics tested.

\section{Solvent resistance of the $P$. putida strains}

P. putida S12 is resistant to organic solvents mainly through the presence of a solvent efflux system (Isken \& de Bont, 1996; Kieboom et al., 1998a). Therefore, it was

\section{Table 3. Solvent tolerance of the $P$. putida strains}

Solvent tolerance of the P. putida strains was determined in LB broth supplemented with $1 \mathrm{mM}$ magnesium chloride. A plus indicates growth with $1 \%$ organic solvent after $24 \mathrm{~h}$ at $30^{\circ} \mathrm{C}$.

\begin{tabular}{|lccccc|}
\hline Solvent & \multicolumn{5}{c|}{ Strain: } \\
\cline { 2 - 6 } & S12 & CM1 & CM2 & JK1 & DM1 \\
\hline $\begin{array}{l}\text { Benzene } \\
\text { Toluene } \\
p \text {-Xylene }\end{array}$ & $\begin{array}{c}10 \mathrm{mM} \\
+\end{array}$ & $\begin{array}{c}10 \mathrm{mM} \\
+\end{array}$ & $\begin{array}{c}10 \mathrm{mM} \\
+\end{array}$ & $6 \mathrm{mM}$ & $6 \mathrm{mM}$ \\
+ & + & + & - & - \\
\hline
\end{tabular}

determined whether the ArpABC efflux pump was involved in solvent resistance in P. putida S12. The antibiotic-sensitive mutant strains CM1 and CM2 were as resistant as the wild-type strain to benzene, toluene and $p$-xylene, whereas the srp-arp double mutant DM1 was as sensitive to organic solvents as the solventsensitive JK1 strain (Table 3). These results indicate that the solvent-resistance phenotype of $P$. putida S12 is not dependent on expression of arpABC genes.

\section{Cloning and induction of the $\operatorname{arp} A B C$ promoter}

To clone and sequence the promoter region and possible regulatory genes of the arp operon, we examined the region upstream of the BamHI site of pCM1B. Therefore, we isolated approximately $3.0 \mathrm{~kb} \mathrm{P}$. putida $\mathrm{S} 12$ chromosomal DNA fragments digested with PstI and EcoRI. These fragments were cloned into pUC18 cut with Pst I and EcoRI. We were able to isolate the plasmid from one colony out of 1200 by colony hybridization 
Table 4. Amino acid sequence identity between $\operatorname{Arp} A B C$ and multidrug and solvent efflux proteins

\begin{tabular}{|c|c|c|c|c|c|c|c|c|}
\hline \multirow[t]{2}{*}{ Organisms } & \multicolumn{8}{|c|}{ Efflux system proteins": } \\
\hline & MFP & Identity (\%) & RND & Identity (\%) & OMP & Identity (\%) & $\mathrm{RP}$ & Identity $(\%)$ \\
\hline \multirow{6}{*}{ P. putida } & ArpA & 100 & ArpB & 100 & ArpC & 100 & ArpR & 100 \\
\hline & $\operatorname{Ttg} \mathrm{A}$ & $99 \cdot 7$ & $\operatorname{Ttg} B$ & $99 \cdot 9$ & $\operatorname{Ttg} C$ & $99 \cdot 6$ & - & - \\
\hline & MepA & $99 \cdot 2$ & MepB & $99 \cdot 9$ & MepC & $99 \cdot 8$ & MepR & $98 \cdot 6$ \\
\hline & $\operatorname{Ttg} \mathrm{D}$ & $58 \cdot 0$ & $\operatorname{Ttg} E$ & $62 \cdot 2$ & $\operatorname{Ttg} F$ & $56 \cdot 6$ & - & - \\
\hline & SrpA & $57 \cdot 1$ & SrpB & $63 \cdot 4$ & SrpC & $57 \cdot 3$ & SrpR & $30 \cdot 9$ \\
\hline & & & & & & & SrpS & $27 \cdot 3$ \\
\hline \multirow[t]{4}{*}{ P. aeruginosa } & MexA & $67 \cdot 6$ & MexB & $78 \cdot 1$ & OprM & $69 \cdot 4$ & MexR & $37 \cdot 5$ \\
\hline & AmrA & $37 \cdot 4$ & $\mathrm{AmrB}$ & $48 \cdot 7$ & - & - & AmrR & $32 \cdot 2$ \\
\hline & MexC & $43 \cdot 1$ & MexD & $48 \cdot 4$ & OprJ & $41 \cdot 6$ & - & - \\
\hline & MexE & $29 \cdot 6$ & MexF & $41 \cdot 4$ & OprN & $28 \cdot 4$ & MexT & $22 \cdot 0$ \\
\hline \multirow[t]{2}{*}{ E. coli } & AcrA & $53 \cdot 8$ & AcrB & $65 \cdot 4$ & TolC & $19 \cdot 3$ & AcrR & $37 \cdot 6$ \\
\hline & AcrE & $50 \cdot 6$ & $\mathrm{AcrF}$ & $64 \cdot 4$ & - & - & EnvR & $30 \cdot 3$ \\
\hline N. gonorrhoeae & MtrC & $43 \cdot 3$ & MtrD & $46 \cdot 6$ & MtrE & $39 \cdot 7$ & MtrR & $33 \cdot 0$ \\
\hline
\end{tabular}

* MFP, membrane fusion protein; RND, efflux protein; OMP, outer membrane protein; RP, regulatory protein. Identity (matches over matches, mismatches and gaps) was calculated with the Lipman-Pearson algorithm using the deduced amino acid sequences of ArpA, ArpB, ArpC and ArpR (GenBank accession no. AF183959); TtgA, TtgB and TtgC (AF031417); MepA, MepB, MepC and MepR (AB008909); TtgD, TtgE and TtgF (PPY19106); SrpA, SrpB and SrpC (AF029405): SrpR and SrpS (AF061937); MexA and MexB (L11616); OprM (L23839); MexR (U23763); AmrA, AmrB and AmrR (AF147719); MexC, MexD and OprJ (U57969); MexE, MexF and OprN (X99514); MexT (AJ007825); AcrA and AcrB (U00734); TolC (X00016); AcrR (U00734); AcrE and AcrF (AE000405); EnvR (X57648); MtrC (U14993); MtrD (U60099); MtrC (X95635) and MtrR (Z25797).

with a $0.7 \mathrm{~kb}$ BamHI-EcoRI fragment from pCM1B. This plasmid, pCMPE, contained the complete promoter region and an ORF $(\operatorname{arpR})$ that was transcribed in the opposite direction to that of $\operatorname{arp} A B C$ (Fig. 1). The $\operatorname{arpR}$ gene product (ArpR) was most similar to MepR $(98.6 \%$ amino acid identity), which is a putative regulator of the MepABC organic solvent transporter (Fukumori et al., 1998) (Table 4). The deduced sequence of $\operatorname{arp} R$ encodes a protein of 210 amino acid residues with a calculated molecular mass of $23.8 \mathrm{kDa}$. Sequence analysis of the ArpR revealed a TetR family signature motif. A putative ribosome-binding site preceded the $\operatorname{arpR}$ gene and a stable stem-loop structure was found downstream of $\operatorname{arpR}$ and may function as transcriptional terminator (Fig. 2). Moreover, a putative $\sigma^{70}$-dependent promoter consensus motif was found upstream of the start of $\operatorname{arp} A$.

The $P$. putida S12 solvent transporter is solely induced by organic solvents (Kieboom et al., 1998b). In this light it was interesting to examine the induction of the multidrug transporter ArpABC. Therefore, the putative promoter region of the $\operatorname{arp} A B C$ operon was amplified by PCR and cloned in the lacZ reporter plasmid pKRZ-1 (Rothmel et al., 1991) cut with XbaI and SalI. The resulting plasmid, designated pKRZ-arp, was electroporated into P. putida S12. P. putida S12(pKRZ-arp) was grown in LB broth in the absence and presence of the antibiotics chloramphenicol, carbenicillin and erythromycin and the solvents toluene, $p$-xylene and hexane. $\beta$-Galactosidase activity was subsequently assayed in late exponential phase $\left(\mathrm{OD}_{600} 1 \cdot 0\right)$. No significant induction was observed by any of these compounds.

\section{DISCUSSION}

In this report we describe the isolation and characterization of chloramphenicol-sensitive mutants from the solvent-tolerant and multidrug-resistant bacterium $P$. putida S12. Two chloramphenicol-sensitive mutants were isolated and sequence analysis showed that both mutants were disrupted in the same operon. Multidrug efflux systems play an important role in the intrinsic resistance of members of the family of Pseudomonadaceae to a variety of antibiotics. At present four antibiotic efflux systems have been described in $P$. aeruginosa: MexAB-OprM (Poole et al., 1993), MexCDOprJ (Poole et al., 1996), MexEF-OprM (Kohler et al., 1997) and AmrAB (Westbrock-Wadman et al., 1999). These systems are involved in the proton-dependent efflux of antimicrobial agents such as $\beta$-lactams, tetracyclines, fluoroquinolones and chloramphenicol. In P. putida TtgABC (Ramos et al., 1998), MepABC (Fukumori et al., 1998) and the ArpABC efflux system described in this report are involved in tolerance towards antibiotics such as tetracycline, chloramphenicol, carbenicillin, streptomycin, erythromycin and novobiocin. Our findings demonstrate that the ArpABC efflux system is a key mechanism in multidrug resistance in P. putida S12.

Proton-dependent efflux systems also play an important role in organic solvent tolerance in P. putida strains 
(Kieboom et al., 1998a; Ramos et al., 1998; Fukumori et al., 1998). The first RND-type efflux system for toluene was isolated by Kieboom et al. (1998) and was shown to be responsible for organic solvent tolerance in P. putida S12 (Kieboom et al., 1998a). The involvement of efflux systems in solvent tolerance was confirmed with the isolation of the $\operatorname{tg} A B C, \operatorname{ttg} D E F$ genes from $P$. putida DOT-T1E (Ramos et al., 1998; Mosqueda \& Ramos, 2000) and the mepABC genes from P. putida KT2442 (Fukumori et al., 1998). Moreover, Kim et al. (1998) reported that a transposon insertion in a protein of the RND family resulted in a $P$. putida mutant with a solvent-sensitive phenotype. Surprisingly, other studies suggested that the isolated solvent transporter in $P$. putida was also involved in the active efflux of multiple antibiotics (Ramos et al., 1998; Fukumori et al., 1998). A toluene-sensitive mepBVTn5 mutant of a $P$. putida KT2442 was also sensitive to ampicillin, penicillin $\mathrm{G}$, erythromycin, novobiocin and tetracycline (Fukumori et al., 1998); and a toluene-sensitive $\operatorname{tg} B \nabla$ mini-Tn $5^{\prime}$ phoA-Km ${ }^{\mathrm{r}}$ mutant of P. putida DOT-T1E was sensitive to chloramphenicol, ampicillin and tetracycline (Ramos et al., 1998). With the construction of a srp-arp double mutant we were able to demonstrate that the ArpABC efflux system was not involved in organic solvent tolerance in P. putida S12.

An interesting, but as yet not completely clear, picture is now emerging from studies on the efflux pumps of pseudomonads with regard to both their substrate recognition and their induction patterns. The inherent problem in studying these aspects is that responses to doses of antibiotics or organic solvents must be monitored at the whole-cell level. Both wild-type cells and mutants may or may not contain additional, and often unknown, pumps. Moreover, the rate of influx of compounds will depend on their chemical structure, while the cell may alter the composition of its cell envelope, thus further obscuring the explanation of results. Nevertheless, on the basis of this type of experimentation it is now possible to distinguish three types of proton-dependent efflux systems in pseudomonads on the basis of compounds expelled from the cell. To date two efflux pumps have been described that are solely involved in the efflux of solvents and do not appear to be able to export antibiotics. This type of efflux pump includes SrpABC in P. putida S12 and TtgDEF in $P$. putida DOT-T1E and was shown to be induced by organic solvents (Kieboom et al., 1998a; Mosqueda \& Ramos, 2000). Most of the efflux systems characterized in pseudomonads, however, export both antibiotics and solvents. These systems include the constitutive TtgABC pump in P. putida DOT-T1E (Ramos et al., 1998), the MepABC pump in P. putida KT2442 (Fukumori et al., 1998) and the Mex efflux systems in $P$. aeruginosa (Li et al., 1998). The third type is the $\operatorname{ArpABC}$ system reported here, which is involved in antibiotic resistance but not in solvent tolerance as shown by the phenotype of the srp-arp double mutant. However, a note of caution in identifying ArpABC as an antibiotic-removing pump and not as a solvent-remov- ing system is appropriate. A solvent pump has to operate at a higher speed than an antibiotic pump due to the considerably higher influx of hydrophobic solvents compared to the influx of antibiotics. Toluene may be present at $5 \mathrm{mM}$ in the aqueous phase, while antibiotics usually remain below $1 \mathrm{mM}$ and it is to be expected that antibiotics will diffuse more slowly into the cell than do uncharged, small solvent molecules. Consequently, solvent efflux pumps may have to generate an efflux that is probably 10-100 times higher than the efflux created by the antibiotic pumps. If the expression level is not affected by the presence of solvent as substrate, as is the case for the ArpABC system, then the solvent-pumping ability may not be registered at the whole-cell level. We have tried to overcome this pitfall by using benzene as test solvent and by employing it at different concentrations. This method should be relatively suitable for detecting minor contributions to solvent pumping, but nevertheless, no effect of the presence of ArpABC on benzene sensitivity was observed.

The grouping of the known Pseudomonas efflux pumps according to their pumping activity for either solvent and/or antibiotics is not supported by the molecular structure of these pumps. The ArpB, TtgB and MepB proteins are almost identical at the amino acid level, which is quite surprising because they have been identified in strains isolated from three very different locations. Also, their $\mathrm{A}$ and $\mathrm{C}$ components are almost identical. ArpB differs only in one amino acid from TtgB (Ala-544 to Gly-544), while compared to MepB it differs in three amino acids (Ala-533 to Thr-533, Ala-544 to Gly-544 and Glu-692 to Ala-692). On the basis of the MexB membrane topology (Guan et al., 1999) it is expected that Ala-544 is located in a putative transmembrane segment, whereas Ala-544 and Glu-692 are periplasmic. These observations would lead to the conclusion that Gly-544 might be a key amino acid in interactions with antibiotics. However, as yet the substrate-binding domain of RND-type proteins has not been identified.

Alternatively, it might be argued that MepABC and TtgABC are present at higher levels in their respective hosts. For P. putida KT2442 it was anticipated that the mep operon was overexpressed in the toluene-tolerant variant TOL. Possibly a similar adaptation phenomenon has taken place already during the isolation of strain $P$. putida DOT-T1E. Therefore, in both strains, a high transcription level of the efflux operons may result in a high solvent efflux, required for the cell to survive in the presence of toluene. Similar results were reported for the mexAB-oprM efflux system in $P$. aeruginosa. In this strain a single substitution in the mexR regulator resulted in the overexpression of MexAB-OprM resulting in an increased multidrug resistance and organic solvent tolerance (Poole et al., 1996; Li et al., 1998; Li \& Poole, 1999).

In summary, the intrinsic resistance of $P$. putida S12 to multiple antibiotics is due to efflux of these components by ArpABC. Whether ArpABC in P. putida S12 is unable 
to transport solvent due to an amino acid substitution or due to the lack of overexpression, the extrusion of organic solvents by this efflux system is too low to prevent their influx but sufficiently high to combat the antibiotic influx. $P$. putida S12 does not have to rely on ArpABC-mediated solvent efflux for its solvent-tolerant phenotype, since it possesses the SrpABC efflux system that is induced under solvent stress.

\section{REFERENCES}

Altschul, S. F., Gish, W., Miller, W., Myers, E. W. \& Lipman, D. J. (1990). Basic local alignment search tool. J Mol Biol 215, 403-410.

Ausubel, F. M., Brent, R., Kingston, R. E., Moore, D. D., Seidman, J. G., Smith, J. A. \& Struhl, K. (editors) (1991). Current Protocols in Molecular Biology. New York: Greene Publishing Associates.

Birnboim, H. C. \& Doly, J. (1979). A rapid alkaline extraction procedure for screening recombinant plasmid DNA. Nucleic Acids Res 7, 1513-1523.

Dennis, J. J. \& Sokol, P. A. (1995). Electrotransformation of Pseudomonas. Methods Mol Biol 47, 125-133.

Dennis, J. J. \& Zylstra, G. J. (1998). Plasposons: modular selfcloning minitransposon derivatives for rapid genetic analysis of Gram-negative bacterial genomes. Appl Environ Microbiol 64, 2710-2715.

Dinh, T., Paulsen, I. T. \& Saier, M. H., Jr (1994). A family of extracytoplasmic proteins that allow transport of large molecules across the outer membranes of gram-negative bacteria. J Bacteriol 176, 3825-3831.

Fukumori, F., Hirayama, H., Takami, H., Inoue, A. \& Horikoshi, K. (1998). Isolation and transposon mutagenesis of a Pseudomonas putida KT2442 toluene-resistant variant: involvement of an efflux system in solvent tolerance. Extremophiles 2, 395-400.

Guan, L., Ehrmann, M., Yoneyma, H. \& Nakae, T. (1999). Membrane topology of the xenobiotic-exporting subunit, MexB, of the MexAB-OprM extrusion pump in Pseudomonas aeruginosa. J Biol Chem 274, 10517-10522.

Hartmans, S., Smits, J. P., van der Werf, M., Volkering, J. F. \& de Bont, J. A. M. (1989). Metabolism of styrene oxide and 2phenylethanol in the styrene degrading Xanthobacter strain 124X. Appl Environ Microbiol 55, 2850-2855.

Isken, S. \& de Bont, J. A. M. (1996). Active efflux of toluene in a solvent-resistant bacterium. J Bacteriol 178, 6056-6058.

Isken, S. \& de Bont, J. A. M. (1998). Bacteria tolerant to organic solvents. Extremophiles 2, 229-238.

Kieboom, J. \& de Bont, J. A. M. (2000). Mechanisms of organic solvent resistance in bacteria. In Bacterial Stress Responses, pp. 393-402. Edited by G. Storz \& R. Hengge-Aronis. Washington, DC: American Society for Microbiology.

Kieboom, J., Dennis, J. J., de Bont, J. A. M. \& Zylstra, G. J. (1998a). Identification and molecular characterization of an efflux pump involved in Pseudomonas putida S12 solvent tolerance. J Biol Chem 273, 85-91.

Kieboom, J., Dennis, J. J., Zylstra, G. J. \& de Bont, J. A. M. (1998b). Active efflux of organic solvents in Pseudomonas putida S12 is induced by solvents. J Bacteriol 180, 6769-6772.

Kim, K., Lee, L., Lee, K. \& Lim, D. (1998). Isolation and characterization of toluene-sensitive mutants from the tolueneresistant bacterium Pseudomonas putida GM73. J Bacteriol 180, 3692-3696.

Kohler, T., Michea-Hamzehpour, M., Henze, U., Gotoh, N., Curty, L. K. \& Pechere, J.-C. (1997). Characterization of the MexE-MexF-
OprN, a positively regulated multidrug efflux system of Pseudomonas aeruginosa. Mol Microbiol 23, 345-354.

Kovach, M. E., Phillips, R. W., Elzer, P. H., Roop, R. M., II \& Peterson, K. M. (1994). pBBR1MCS : a broad-host-range cloning vector. Biotechniques 16, 801-802.

Li, X.-Z. \& Poole, K. (1999). Organic solvent-tolerant mutants of Pseudomonas aeruginosa display multiple antibiotic resistance. Can J Microbiol 45, 18-22.

Li, X.-Z., Zhang, L. \& Poole, K. (1998). Role of the multidrug efflux systems of Pseudomonas aeruginosa in organic solvent tolerance. J Bacteriol 180, 2987-2991.

Maniatis, T. E., Fritsch, E. F. \& Sambrook, J. (1982). Molecular Cloning: a Laboratory Manual. Cold Spring Harbor, NY: Cold Spring Harbor Laboratory.

Miller, J. (1972). Experiments in Molecular Biology. Cold Spring Harbor, NY: Cold Spring Harbor Laboratory.

Mosqueda, G. \& Ramos, J. L. (2000). A set of genes encoding a second toluene efflux system in Pseudomonas putida DOT-T1E is linked to the tod genes for toluene metabolism. J Bacteriol 182, 937-43.

Nikaido, H. (1994). Prevention of drug access to bacterial targets: role of permeability barriers and active efflux. Science 264, 382-388.

Nikaido, H. (1996). Multidrug efflux pumps of Gram-negative bacteria. J Bacteriol 178, 5853-5859.

Paulsen, I. T., Brown, M. H. \& Skurray, R. A. (1996). Protondependent multidrug efflux systems. Microbiol Rev 60, 575-608.

Poole, K., Krebes, K., McNally, C. \& Neshat, S. (1993). Multiple antibiotic resistance in Pseudomonas aeruginosa: evidence for involvement of an efflux operon. J Bacteriol 175, 7363-7372.

Poole, K., Tetro, K., Zhao, Q., Neshat, S., Heinrichs, D. E. \& Bianco, N. (1996). Expression of the multidrug resistance operon mexAmexB-oprM in Pseudomonas aeruginosa: mexR encodes a regulator of operon expression. Antimicrob Agents Chemother 40, 2021-2028.

Ramos, J. L., Duque, E., Godoy, P. \& Segura, A. (1998). Efflux pumps involved in toluene tolerance in Pseudomonas putida DOT-T1E. J Bacteriol 180, 3323-3329.

Rothmel, R. K., Shinabarger, D. L., Parsek, M. R., Aldrich, T. L. \& Chakrabarty, A. M. (1991). Functional analysis of the Pseudomonas putida regulatory protein CatR: transcriptional studies and determination of the CatR DNA-binding site by hydroxylradical footprinting. J Bacteriol 173, 4717-4724.

Saier, M. H., Jr, Tam, R., Reizer, A. \& Reizer, J. (1994). Two novel families of bacterial membrane proteins concerned with nodulation, cell division and transport. Mol Microbiol 11, 841-847.

Sambrook, J., Fritsch, E. F. \& Maniatis, T. (1989). Molecular Cloning: a Laboratory Manual, 2nd edn. Cold Spring Harbor, NY: Cold Spring Harbor Laboratory.

Vogelstein, B. \& Gillespie, D. (1979). Preparative and analytical purification of DNA from agarose. Proc Natl Acad Sci US A 76, 615-619.

Weber, F. J. \& de Bont, J. A. M. (1996). Adaptation mechanisms of microorganisms to the toxic effects of organic solvents on membranes. Biochim Biophys Acta 1286, 225-245.

Weber, F. J., Ooijkaas, L. P., Schemen, R. M. W., Hartmans, S. \& de Bont, J. A. M. (1993). Adaptation of Pseudomonas putida S12 to high concentrations of styrene and other organic solvents. Appl Environ Microbiol 59, 3502-3504.

West, S. E., Schweizer, H. P., Dall, C., Sample, A. K. \& RunyenJanecky, L. J. (1994). Construction of improved Escherichia- 
Pseudomonas shuttle vectors derived from pUC18/19 and sequence of the region required for their replication in Psendomonas aeruginosa. Gene 148, 81-86.

Westbrock-Wadman, S., Sherman, D. R., Hickey \& 7 other authors (1999). Characterization of a Pseudomonas aeruginosa efflux pump contributing to aminoglycoside impermeability. Antimicrob Agents Chemother 43, 2975-83.
Yanisch-Perron, C., Vieira, J. \& Messing, J. (1985). Improved M13 phage cloning vectors and host strains: nucleotide sequences of the M13mp18 and pUC19 vectors. Gene 33, 103-119.

Received 17 May 2000; revised 25 August 2000; accepted 19 September 2000. 